REVIEW

\title{
Does wine prevent dementia?
}

\author{
Roger M Pinder \\ Pharma Consultant, York, UK
}

Correspondence: Roger M Pinder

2 St. Wilfrid's Court, Monkgate,

York YO3I 7UQ, UK

Tel +44 1904646684

Email roger.pinder@gmail.com

\begin{abstract}
There is substantial evidence that moderate consumption of alcohol reduces significantly the risks of coronary heart disease, stroke and type 2 diabetes. Furthermore, the incidence of dementia, both of the Alzheimer's type (AD) and the vascular variety (VaD), is lower in societies which consume a Mediterranean diet of mainly fish, fruit, vegetables, olive oil, and wine. In particular, extensive evidence from both population-based cohort and case control studies in different areas of the world and across genders and racial groups suggests that regular consumption of moderate amounts of alcohol, especially in the form of wine, is associated with a lower risk of developing $\mathrm{AD}$ and $\mathrm{VaD}$ compared with abstention and heavy drinking. Carriers of the APOE $\varepsilon 4$ allele seem to gain less benefit. Age-related cognitive decline, particularly in women, is lower in regular drinkers, while older drinkers with Mild Cognitive Impairment (MCI) progress less frequently to $\mathrm{AD}$ than their abstaining counterparts. Plausible biological mechanisms for the neuroprotective effects of wine include its glucose-modifying, antioxidant and inflammatory properties, but it additionally seems to modify the neuropathology of AD, particularly the deposition of amyloid plaque. Indeed, some of these mechanisms are already targets for the development of new therapeutic agents for the treatment of dementia.
\end{abstract}

Keywords: alcohol, Alzheimer's disease, dementia, epidemiology, polyphenols, wine

\section{Introduction}

Alcohol and particularly wine have a long history dating from neolithic times, and their use in medicine is also very old. ${ }^{1}$ Their medical applications have been manifold, and especially in the beginning they were principally used for antimicrobial and antifungal purposes. ${ }^{2}$ The advent of modern clinical epidemiology has allowed the many traditional uses of alcohol and wine as medicines to be put to serious testing. Thus, prospective population-based studies have amply demonstrated the protective effects of moderate daily consumption of alcohol in lowering the overall risk of coronary heart disease (CHD), including myocardial infarction, by about $35 \%{ }^{3-5}$ and of total mortality by $17 \%-18 \% .{ }^{6}$ Moderate alcohol consumption even protects already hypertensive individuals against both $\mathrm{CHD}^{7}$ and heart failure. ${ }^{8}$ It also seems to protect against ischemic stroke, with overall reductions in risk of about $20 \%-28 \%$, and women benefitting most from moderate drinking with a $21 \%-34 \%$ risk reduction. ${ }^{9,10}$ Hemorrhagic stroke is relatively unaffected by alcohol consumption, except for slight protection at very low levels of consumption and a much enhanced risk in heavy drinkers. The risk of type 2 diabetes is also lowered by moderate consumption of alcohol to an extent of about $30 \%,{ }^{11,12}$ and is associated with beneficial effects on glucose and insulin levels and on insulin sensitivity. ${ }^{13}$ Association is not synonymous with causality, and total independence from confounders cannot be established in observational data. However, Klatsky ${ }^{14}$ concluded that, at least for $\mathrm{CHD}$, the consistency of results in worldwide studies of case-control and prospective designs across racial groups and both genders, coupled with evidence of plausible biological mechanisms in the enhancing effect of alcohol on high-density lipoprotein (HDL) and its probable anti-thrombotic effects, 
were sufficient basis to conclude that the drink and not the drinker was responsible for the lowered risk.

It is the purpose of this review to address the issue of whether the consumption of alcohol, and in particular wine, has a similar beneficial effect upon the risks of dementia, both Alzheimer's dementia (AD) and vascular dementia (VaD) in the elderly. The issue of drinking and cognition in old age, and particularly of Mild Cognitive Impairment (MCI) which is a harbinger of $\mathrm{AD}^{15}$ will also be covered. A systematic review of the field has recently been published. ${ }^{16}$

\section{Dementia}

Dementia is a syndrome characterized by a progressive global deterioration in intellectual function. $\mathrm{AD}$ is the most common pathology, accounting for $50 \%-75 \%$ of cases. The prevalence of dementia in developed countries rises with age, from about $1 \%$ in those aged $60-64$ years to over $45 \%$ in those aged 95 years and over. ${ }^{17}$ Recent estimates for numbers suggest that $18-25$ million persons were affected in 2000, and that this number will double by 2020. Demographic aging in China, India, and Latin America will probably add to these numbers. Some symptomatic treatments for $\mathrm{AD}$ are available in the form of the cholinesterase inhibitors donepezil, galantamine, and rivastigmine, as well as the NMDA receptor antagonist memantine, but the search is on for disease-modifying therapies. Current therapeutic targets include the enzymes involved in the formation and degradation of the amyloid or tau proteins which are responsible for the classical AD neuropathology of plaques and tangles. ${ }^{18}$ Therapeutic vaccines are also being developed to target aberrant proteins as soon as they appear in the aging brain.

There is also substantial evidence that some commonly used drugs and lifestyle factors may play important neuroprotective roles in lowering the risk for $\mathrm{AD} .{ }^{19,20}$ The incidence of $\mathrm{AD}$ seems to be lessened in users of statins, antihypertensives and nonsteroidal anti-inflammatory drugs (NSAIDs), such that some of the new disease-modifying agents are structural variants of traditional NSAIDs. However, clinical trials of standard NSAIDS in AD have proved not to improve cognitive function. ${ }^{21,22}$ Antioxidants, nicotine and control of blood glucose may also be important risk modifiers. Life style factors like mental and physical exercise, as well as diet, have been shown in large-scale community-based studies to play important roles. For example, those people with substantial cognitive reserve in old age seem less likely to manifest the symptoms of $\mathrm{AD}$ in the face of ongoing pathology. ${ }^{23}$ There is also a lower incidence of MCI and AD in societies which consume a Mediterranean diet of mainly fish, fruit, vegetables, olive oil, and wine. ${ }^{20}$ Meta-analysis of studies involving over 1.5 million subjects revealed an overall risk reduction of about $13 \%,{ }^{24}$ while intervention studies in the elderly in New York City have shown a $40 \%$ reduction in $\mathrm{AD}$ risk $^{25}$ and a $35 \%$ reduction in mortality in those who developed AD. ${ }^{26}$ In the Three-City Cohort Study carried out in 8085 French subjects aged 65 years or older there were 281 incident cases of dementia during a 4-year follow-up, 183 of which were AD. Regular consumption of fruit and vegetables, of fish, and of $\omega-3$ rich oils reduced the risk for dementia including AD by between 38\% and 54\%. ${ }^{27}$ Weekly consumption of fish or seafood significantly reduced the risk of incident dementia (relative risk [RR] 0.66) in the large PAQUID cohort in south-western France. ${ }^{28}$

\section{Type of alcoholic beverage and patterns of use}

The choice of alcoholic beverage is important, although in many studies the issue is confounded by small numbers and nonexclusive drinking habits: many of us drink wine, both white and red, as well as beer and distilled spirits. It seems that moderate drinkers of alcohol have a lower risk of cardiovascular disease when their preferred beverage is wine rather than beer, ${ }^{3}$ as well as a lower risk of all-cause mortality especially from CHD when wine is preferred to beer or spirits. ${ }^{4,6}$ Whether the reduced risks are associated with the nonalcoholic constituents of wine or to drinking patterns and other traits of wine drinkers is unclear.

Many population-based studies have demonstrated that wine drinkers have healthier life-style habits than their beer or spirit-drinking counterparts - they are more often women, college graduates, nonsmokers, and temperate drinkers. ${ }^{4,29}$ Indeed, Klatsky ${ }^{14}$ remarked on the fact that circumstantial evidence only raises a probability, and that it may be the drinker and not the drink that produces the benefit. Nevertheless, in the case of dementia it appears that wine may confer a greater advantage in risk reduction than beer or spirits. . $^{10,16,30}$

Apart from the choice of beverage, the pattern of drinking is also an important factor. What constitutes light, moderate and heavy drinking is often in the eye of the beholder. Moreover, averaging alcohol consumption can be problematical in epidemiological studies because individuals can maintain identical averages by taking one drink daily or seven drinks on one day of the week, with very different consequences. ${ }^{5}$ Many studies have indicated that daily consumption is important, although Mukamal and colleagues ${ }^{31,32}$ have suggested that consumption of alcohol on 3-4 days per week may be associated with the lowest risk of myocardial infarction in 
men with CHD with red wine providing the most benefit in preventing ischemic stroke. ${ }^{33}$ Binge drinking, on the other hand, may double the risk of mortality after myocardial infarction. ${ }^{34}$ This also appears to be the case with dementia, where the Finnish twin study has demonstrated that various degrees of binge drinking may raise the risk of AD by 3- to 10-fold. ${ }^{35}$

Most population-based studies have used an operational definition with a boundary of moderate daily consumption of two standard drinks, a level above which net harm is often observed. ${ }^{5}$ However, light to moderate drinking is sometimes taken to mean a daily consumption of three standard drinks or less, while gender, age and culture may lower and raise the boundary for individuals. There is a tendency to set lower limits for women based upon differences in body fat from men, but there are really no convincing data on harm to support this notion. Finally, many participants in studies, especially heavy drinkers, lie about their consumption, thus lowering the apparent threshold for harmful effects of alcohol in community-based samples. Nevertheless, since the first demonstration of an association between wine consumption and cardiac mortality, ${ }^{36}$ the existence of the J-shaped curve, whereby abstainers and heavy drinkers fare worse than light to moderate drinkers, has remained stable over three decades.

The amount of alcohol is approximately the same in a standard-sized drink of each of the three main categories of beverage, comprising $15 \mathrm{ml}$ or approximately $12.5 \mathrm{~g}$ of ethanol. This represents a glass of wine of $120 \mathrm{ml}$ (4 US ounces) at $12.5 \%$ alcohol, a glass of beer of $360 \mathrm{ml}$ (12 US ounces) at $4 \%$ alcohol, and a glass of distilled spirits of $37.5 \mathrm{ml}$ (1.25 US ounces) at 40\% alcohol. However, the availability of wines, beers, and spirits of varying alcohol content which are being served in different measures leaves room for misinterpretation of average alcohol consumption, especially when most consumers only think in terms of drinks. The use of widely different units in government guidelines in various countries does not help, with the UK and Ireland having the lowest unit at $8 \mathrm{~g}$ alcohol, Australia and New Zealand at $10 \mathrm{~g}$, much of Europe at $12 \mathrm{~g}$, Canada and the USA at about $14 \mathrm{~g}$, and Japan the highest at $19.75 \mathrm{~g}$. Some of the complexities emerged in the large meta-analysis of studies on stroke and alcohol consumption; ${ }^{9} 20 / 35$ studies reported in grams per day, while the others used standard drinks defined as $12 \mathrm{~g}$ in the USA, $10 \mathrm{~g}$ in Australia, and a generous $21.2 \mathrm{~g}$ in Japan. Most epidemiological studies on alcohol and dementia have divided drinkers into groups based upon daily consumption in grams, with $12-24 \mathrm{~g}$ daily being taken as moderate and $<12$ g daily as light drinking. Only few studies have divided abstainers into those who have never drunk alcohol and those who have previously been drinkers but stopped at some time in the past.

\section{Wine and dementia}

Some studies have shown no relationship between moderate alcohol consumption and incident dementia: Hébert and colleagues, both in a community in Boston, Massachusetts ${ }^{37}$ and in the Canadian Study of Health and Aging ${ }^{38}$ showed no association between incident $\mathrm{AD}$ and $\mathrm{VaD}$ respectively and alcohol consumption. Furthermore, studies in communities in Sydney, Australia ${ }^{39}$ and Hisayama, Japan. ${ }^{40}$ have also failed to find such an association.

It is intriguing, however, that moderate drinking in the small town of Dubbo in rural New South Wales was associated with a $34 \%$ lower risk of dementia ${ }^{41}$ whereas there was no such effect in the much larger city of Sydney; ${ }^{39}$ physical activity was also an important factor for reducing dementia risk in Dubbo. Larger amounts of alcohol, including wine, in the form of binge drinking have a detrimental effect on the risk of dementia, raising the risk by as much as 10 -fold in a Finnish population. ${ }^{35}$ Other Finnish population-based studies have shown that moderate consumption of alcohol is associated with a significant reduction in the risk of dementia. ${ }^{42,43}$

The largest systematic review of alcohol consumption and the risk of dementia has recently been published. ${ }^{16}$ Metaanalyses of the identified 23 studies suggested that low to moderate amounts of alcohol are associated with a significantly reduced risk of $38 \%$ (RR 0.63 ) for all dementia and $32 \%$ for $\mathrm{AD}$ (RR 0.57). The reduction in risk for $\mathrm{VaD}$ ( $\mathrm{RR}$ 0.82 ) was not statistically significant. Studies for the current review, which focuses on wine rather than just alcohol, were selected on the basis that they differentiated beverage types. Thus, substantial evidence from both population-based cohort and case control studies suggest that regular consumption of moderate amounts of alcohol, especially in the form of wine as in the Mediterranean diet, is associated with a lower risk of developing dementia, both $\mathrm{AD}$ and $\mathrm{VaD}$, compared with abstainers and heavy drinkers (Table 1, Figure 1).

The first prospective study took place in the Bordeaux region of France, where wine is the principal form of alcohol consumed and usually on a daily basis. ${ }^{44}$ The PAQUID study sampled 3,777 subjects aged 65 years and older who were followed up for three years, during which period 99 cases of incident dementia were diagnosed of which 66 were classified as $\mathrm{AD}$. Information on alcohol consumption was collected at baseline and the participants were divided into nondrinkers, 
Table I Population-based studies of wine consumption and dementia ${ }^{10,16,30}$

\begin{tabular}{|c|c|c|c|}
\hline Authors & Study type & $\begin{array}{l}\text { No. of } \\
\text { subjects }\end{array}$ & Region \\
\hline Orgogozo et al ${ }^{44}$ & Cohort & 3,777 & Bordeaux \\
\hline Leibovici et $\mathrm{al}^{45}$ & Cohort & 397 & France (south) \\
\hline Huang et $\mathrm{a}^{49}$ & Cohort & 402 & Sweden \\
\hline Lindsay et a $\mathrm{a}^{48}$ & Cohort & 6,434 & Canada \\
\hline Ruitenberg et a ${ }^{46}$ & Cohort & 7,983 & Rotterdam \\
\hline Truelsen et $\mathrm{al}^{53}$ & Case control & I,709 & Copenhagen \\
\hline Mukamal et al $\left.\right|^{52}$ & Case control & 746 & USA \\
\hline Larrieu et $\mathrm{a}^{28}$ & Cohort & 2,950 & $\begin{array}{l}\text { France } \\
\text { (southwest) }\end{array}$ \\
\hline Luchsinger et a ${ }^{47}$ & Cohort & 980 & USA (NYC) \\
\hline Deng et $\mathrm{al}^{50}$ & Cohort & 2,632 & China \\
\hline Mehlig et a ${ }^{54}$ & Cohort & $\mathrm{I}, 462$ & $\begin{array}{l}\text { Göteborg, } \\
\text { Sweden }\end{array}$ \\
\hline
\end{tabular}

mild drinkers (1-2 drinks daily), moderate drinkers (3-4 drinks daily) and heavy drinkers ( $>4$ drinks daily); $95 \%$ of regular drinkers consumed only wine. After adjustment for age, sex, education, occupation, baseline Mini-Mental State Examination (MMSE) and other possible confounders, odds ratios (OR) were 0.19 for incident dementia and 0.28 for AD when moderate drinkers (318 subjects) were compared with nondrinkers $(n=971)$. The 922 mild drinkers showed a lesser protective effect and only with AD (OR 0.55). All differences were statistically significant.

A second French study, carried out on a cohort of 397 elderly subjects living in the south of France followed up for three years, studied the effect of wine and tobacco consumption on cognitive performance in the elderly. ${ }^{45}$ While smoking had no protective effect against AD, wine consumption was significantly associated with a four-fold diminishing of the risk (OR 0.26). This benefit was apparent only in those still living in the community, and disappeared when subjects were institutionalized.

Confirmation of these initial French studies took some time, but four years later a prospective community-based study in Rotterdam in the Netherlands was reported. ${ }^{46}$ A cohort of 7,983 individuals aged 55 years and older were followed up for six years, during which period 197 incident cases of dementia (146 AD, $29 \mathrm{VaD}, 22$ others) were diagnosed. The number of drinks of alcoholic beverages was collected at baseline, and participants were divided into nondrinkers, those drinking less than one drink per week, or more than one drink per week but less than one per day, or 1-3 drinks daily, or more than three drinks daily. Light to moderate drinking (1-3 drinks daily) was significantly associated with a lower risk of any dementia (hazard ratio [HR] 0.58) and $\mathrm{VaD}$ (HR 0.29). Men gained more benefit than women, and the risk was lower among drinkers who carried the apolipoprotein $\mathrm{E}$ $\varepsilon 4$ allele (APOE \&4) but it was less clear for drinkers without the allele. No significant differences were found between beverage types, although beer tended to give marginally lower risk than wine.

A third French study following up the large PAQUID cohort of almost 3,000 subjects aged over 65 years and living in the community in southwestern France also confirmed these results. ${ }^{28}$ The overall incidences of dementia and AD over eight years of follow-up were 1.74 and 1.48 per 100 person-years, respectively. Moderate consumers of wine had a significantly decreased risk of developing any dementia (RR 0.56) and AD (RR 0.53).

In another prospective community-based cohort study of 980 subjects aged 65 years and older living in northern Manhattan, there were 260 incident cases of dementia (199 AD, $61 \mathrm{VaD}$ ) during four years of follow-up. ${ }^{47}$ Subjects were classified at baseline as nondrinkers, light $(<1$ drink per month to 6 drinks per week), moderate (1-3 drinks daily) and heavy drinkers ( $>3$ drinks daily). Because $70 \%$ of the sample were nondrinkers, the light and moderate groups were amalgamated into a group in which wine was significantly associated with a lower risk for dementia (HR 0.64). After adjusting for age, sex, APOE $\varepsilon 4$ status, education, and other alcoholic beverages, only intake of up to three daily servings of wine was associated with a lower risk of $\mathrm{AD}$ (HR 0.55). The association between wine consumption and the lower risk of $\mathrm{AD}$ was confined to individuals without the APOE $\varepsilon 4$ allele.

Several other prospective cohort studies from different parts of the world have also reported an association between alcohol consumption and dementia (Table 1). The Canadian Study of Health and Aging was a nationwide, populationbased study of 6,434 subjects aged 65 years or older, who were followed up for five years during which period 195 cases of AD were diagnosed..$^{48}$ Use of NSAIDs, wine consumption, coffee consumption, and regular physical exercise were all associated with a reduced risk of AD. At least weekly consumption of wine (OR 0.49) and alcohol of any type (OR 0.68 ) were significantly associated with a reduced risk of $A D$, whereas consumption of beer or spirits were not. In Sweden, a community-based cohort of 402 elderly subjects was followed up for almost six years. ${ }^{49}$ Light to moderate drinking was significantly associated with a decreased risk of incident dementia and AD compared with abstention (RR 0.5). 


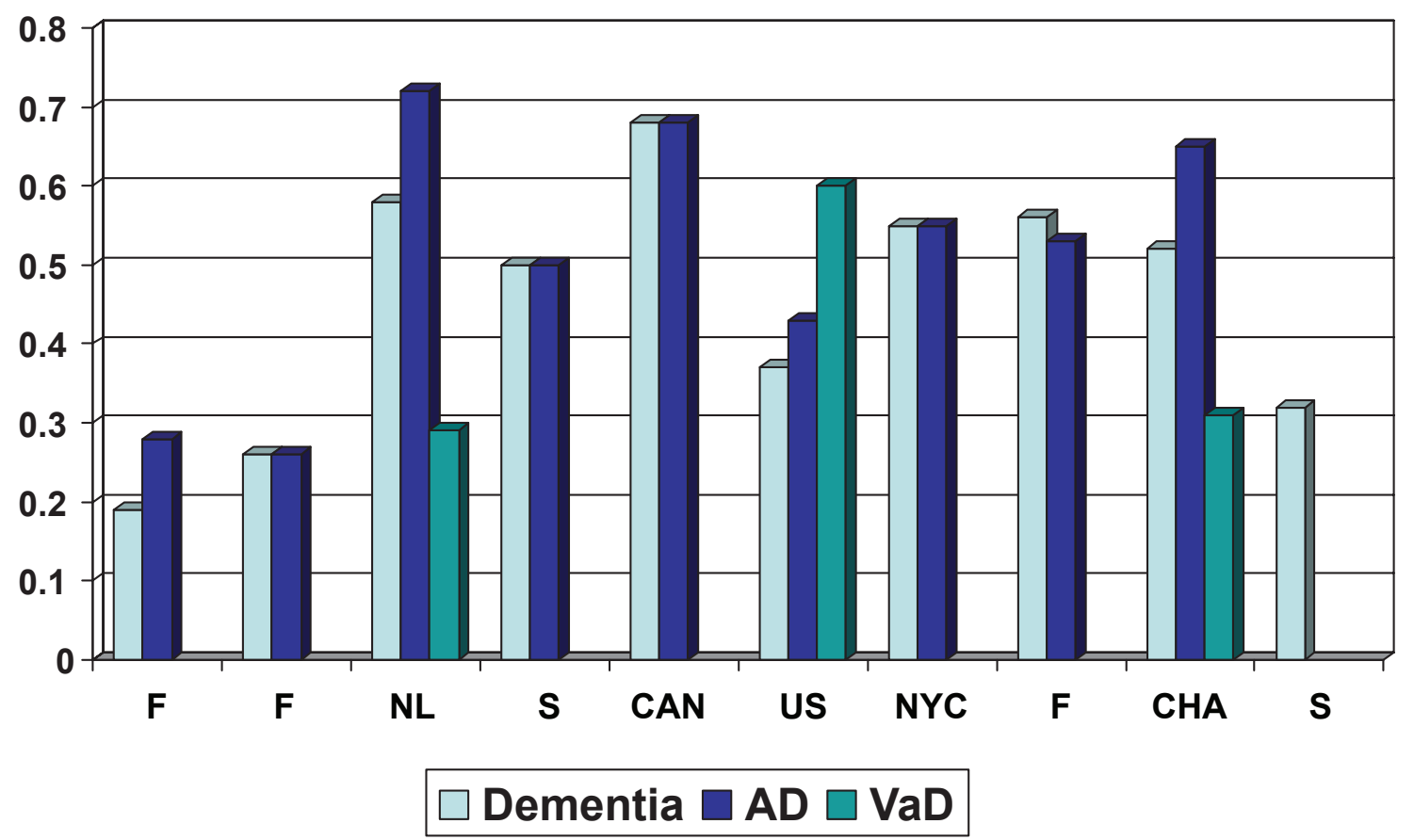

Figure I Risk of dementia in moderate drinkers relative to abstainers. Orgogozo and colleagues ${ }^{44}$ (Bordeaux); Leibovici and colleagues ${ }^{45}$ (southern France); Ruitenberg and colleagues $^{46}$ (Rotterdam); Huang and colleagues ${ }^{49}$ (Sweden); Lindsay and colleagues ${ }^{48}$ (Canada); Mukamal ${ }^{52}$ (USA); Luchsinger and colleagues ${ }^{47}$ (northern Manhattan); Larrieu and colleagues $^{28}$ (southwest France); Deng and colleagues ${ }^{50}$ (Chongqing, China); Mehlig and colleagues ${ }^{54}$ (Göteborg, Sweden). HR, OR, and RR values are described in the text.

In Chongqing, China, a two-year follow-up of 2,632 subjects aged 60 years or older revealed a significantly lower risk (RR 0.52 ) of dementia for light to moderate drinkers (1-21 drinks per week for men and 1-14 for women) than abstainers. ${ }^{50} \mathrm{~A}$ greater reduction in risk was observed for men (RR 0.37) than for women (RR 0.76). Alcohol consumption reduced the risk of $\mathrm{VaD}(\mathrm{RR} 0.31)$ and other dementias $(0.45)$ more than that for $\mathrm{AD}(0.63)$. Heavy drinking raised the risk of dementia in Chinese drinkers as did light to moderate beer consumption, but wine was associated with a significantly lower risk of dementia compared to abstainers. However, a second study from Chongqing of 434 consecutive patients admitted with ischemic stroke suggested that daily drinking tripled the risk of post-stroke dementia, presumably VaD, during the 3 months immediately after the event. ${ }^{51}$

Two nested case control studies have explored the association between alcohol consumption and the risk for dementia within the context of larger studies designed to examine cardiovascular events, one in the Cardiovascular Health Study in 4 communities in the US states of California, Maryland, North Carolina and Pennsylvania ${ }^{52}$ and the other in the setting of the Copenhagen City Heart Study. ${ }^{53}$ The US study included 373 cases of dementia and a similar number of matched controls, and defined weekly levels of alcohol consumption as 0 , less than $1,1-6,7-13$, or more than 14 drinks. For all subjects, alcohol consumption and the risk of dementia followed the classical J-shaped curve with the 1-6 drinks weekly group at the nadir of the J; however, this was only true for men whereas women experienced a lower risk of dementia at all levels of alcohol consumption. The presence of the APOE $\varepsilon 4$ allele eliminated the lowered risk of dementia in all groups. Beer and spirits conferred no significant benefit at any level of weekly consumption, but the risk of dementia was lower, though not significantly so, in wine drinkers at levels of one or 1-6 drinks weekly (HR 0.72) and in the group who drank more than six drinks per week (HR 0.62). The Copenhagen City Heart Study included 83 cases of dementia and 1626 controls, whose alcohol consumption was measured both by the number of weekly drinks ( $<1,1-7,8-14,15-21,22$ or more) and by frequency (never/hardly ever, monthly, weekly, daily). There was no association between the number of drinks consumed per week and the risk of dementia for all drinkers. However, a significant reduction in risk was found for wine drinkers (HR: monthly 0.43 , weekly 0.33 , daily 0.57 ). Beer drinkers tended to have a higher risk, while no clear association was found in spirits drinkers. There were no differences between men and women. 
Finally, a prospective community-based study followed 1,462 women aged 38 to 60 years and living in Göteborg, Sweden in $1968-1969$, for 34 years. ${ }^{54}$ In 2002 there were 164 cases of dementia. Wine consumption was significantly protective for dementia (HR 0.6) and the association was strongest among women who consumed only wine (HR 0.3). After stratification by smoking, the protective association of wine was stronger among smokers. In contrast, consumption of spirits was associated with a slightly increased risk of dementia (HR 1.5), while beer drinking had no net effect either way.

Another relevant study not listed in Table 1 was of a different, cross-sectional, design to the prospective communitybased studies described above, and focused primarily upon cognitive function rather than dementia. ${ }^{55}$ Using the GIFA database of adverse drug reactions in hospitalized patients, all 15,807 individuals admitted to 81 academic hospitals throughout Italy during specific two-month periods in 1993 , 1995 and 1997 were enrolled and observed until discharge. Cognitive impairment was observed in significantly less of the alcohol drinkers, 1693/8755 (19\%) than in the abstainers, 2008/7052 (29\%). After adjustment for possible confounders, alcohol consumption was associated with a significantly decreased probability of cognitive impairment in the total sample (OR 0.75). In both subgroups of $\mathrm{AD}$ and stroke patients, alcohol consumption was also associated with a decreased probability of cognitive impairment, reducing the respective risks by $29 \%$ (OR 0.71 ) and $34 \%$ (OR 0.66 ), respectively (Figure 2). These benefits in the Italian elderly were associated with daily alcohol consumption of less than $40 \mathrm{~g}$ for women and less than $80 \mathrm{mg}$ for men; given the pattern of drinking red wine with meals in this population, it is likely that the benefit can be attributed to wine.

The studies summarized in Table 1 and Figure 1, and described in more detail above, have amply demonstrated that moderate alcohol consumption protects in some way against dementia particularly $\mathrm{AD}$ and in some cases also $\mathrm{VaD}$. It seems that a daily, or possibly 3-4 times weekly, pattern of drinking is best. The balance of evidence strongly supports the notion that wine gives more protection than beer while spirits are sometimes damaging (Table 2), a view also partly confirmed in the large meta-analysis of Peters and colleagues. ${ }^{16}$

\section{Wine and cognition}

Given the evidence that moderate consumption of alcohol, particularly wine, substantially reduces the risk of dementia, there is every reason to believe that it would also effect cognitive decline during aging. However, the recent systematic review of Peters and colleagues ${ }^{16}$ concluded that small amounts of alcohol were not significantly protective for cognitive decline in the elderly (RR 0.89). Furthermore, in

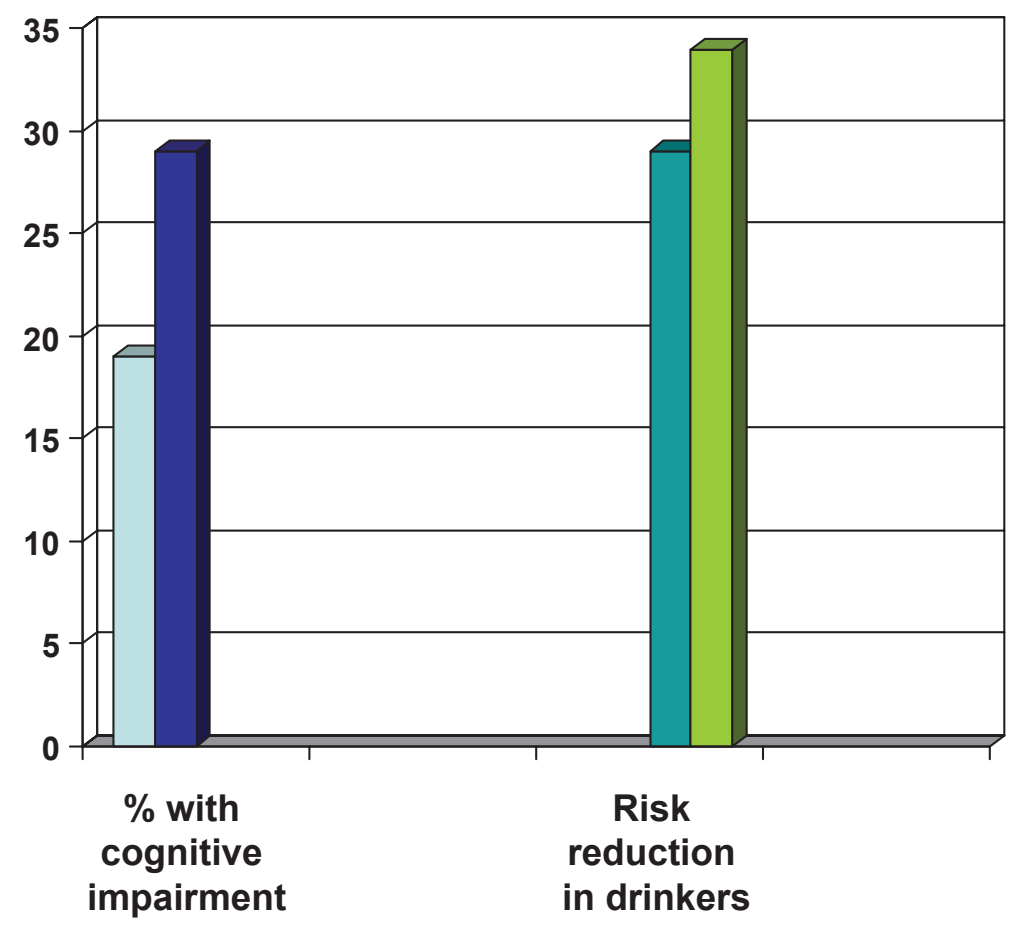

Drinkers $(\mathrm{n}=\mathbf{8 7 5 5})$

Abstainers $(n=7052)$

Alzheimer's patients

Stroke patients

Figure 2 Alcohol consumption and cognitive impairment in the Italian elderly. ${ }^{55}$ 
Table 2 Is wine responsible for the protective effects of alcohol on the risk of dementia?

- In favor of wine: studies in Bordeaux, France (south), France (southwest), Copenhagen, Canada, USA (CA, MD, NC, PA), New York (northern Manhattan), China (Chongqing) and Göteborg (Sweden)

- No difference between wine, beer, and spirits: studies in Sweden and Rotterdam

the community-based study in Boston which established no association between alcohol consumption and risk of dementia, ${ }^{37}$ low to moderate alcohol consumption was not significantly related to cognitive function during a three-year follow-up period. ${ }^{56}$ However, both the Rotterdam study, ${ }^{46}$ which looked at the association between alcohol consumption and the risk of dementia, and the Italian elderly study, ${ }^{55}$ which focused on cognition, concluded that cognitive decline in old age was less in drinkers (see Figure 2).

A number of other community-based studies have reported similar findings ${ }^{57-61}$ that light to moderate drinkers have better cognition than abstainers, particularly in old age with women benefitting more than men. Again J- or U-shaped curves are common, where heavy drinking is associated with worse cognitive functioning. The latest reports on a number of long-term cohorts have also reported similar findings:

- The UK Whitehall Study of 4,272 male and 1,761 female civil servants followed up for about 11.5 years showed that cognitive function was significantly better in drinkers, even in those drinking more than $240 \mathrm{~g}$ alcohol per week, with benefit being greater in women and not confined to those subjects with vascular disease. ${ }^{62}$

- The US Nurses' Health Study of 12,480 female nurses followed up for 15-20 years found that moderate drinkers ( $<15 \mathrm{~g}$ alcohol/day) had better cognition than abstainers, with relative risks in drinkers of around $0.77-0.81$ for various cognitive measures. ${ }^{63}$ Higher levels of alcohol use did not alter the risks for cognitive impairment or decline.

- The Women's Health Initiative Memory Study of 4,461 postmenopausal women aged 65-79 years taking combination hormone replacement therapy followed up for an average of 4.2 years showed that drinkers had significantly higher MMSE scores and less cognitive decline than abstainers. ${ }^{64}$ Women who consumed about a drink a day $(<15 \mathrm{~g}$ alcohol) scored about a year and a half younger in their mental performance than the nondrinkers. Moderate alcohol intake was also associated with about a $50 \%$ reduced risk of combined probable dementia and MCI, the significance of which disappeared after adjustment for demographic and socioeconomic factors and baseline MMSE scores.

- The Northern Manhattan Study of 1,428 Hispanic, black and white individuals showed a positive association between reported alcohol intake and cognition. Subjects who consumed less than one drink per week, or between one drink weekly and two drinks daily, or more than two drinks daily all had lesser cognitive decline than subjects who had never drunk alcohol. ${ }^{65}$

- The Australian Longitudinal Study on Women's Health, which included women who were between 70 and 75 years of age in 1996 followed up through 2002, reported that women who rarely or did not drink alcohol were more likely to die than those who drank two drinks daily on three to six days of the week and scored lower on measures of mental health and social functioning. ${ }^{66}$

- The Cardiovascular Risk Factors Aging and Dementia (CAIDE) Study in Finland followed 1,341 subjects for about 21 years at which point they were 65-79 years old. ${ }^{67}$ Drinkers at both midlife and later had better cognitive function in several domains including episodic memory, executive function and psychomotor speed than nondrinkers.

- A longitudinal community-based study in Pittsburgh residents with an average age of 74 years assessed every two years over an average of seven years of follow-up found that light to moderate drinking was associated with lesser decline on the MMSE and several cognitive tests when compared to lifelong abstainers and those who had stopped drinking. ${ }^{68}$

Other designs of studies have confirmed the cohort findings. The New Mexico Elder Health Survey, a crosssectional community survey of 883 randomly selected Hispanic and non-Hispanic white men and women aged 65 years or older, showed that participants who consumed alcohol had significantly better scores on seven of nine cognitive function tests than those who abstained. ${ }^{69}$ In a case control study performed in 208 pairs of elderly Danish women with a mean age of 73.2 years, cases with impaired cognition were compared with normal controls, matched by age and educational status. ${ }^{70}$ Lifestyle practices, co-morbid disorders and genotypes were compared using multivariate analyses. Cognitive decline was greater in women who had a history of depression or the metabolic syndrome and those who were carriers of the APOE $\varepsilon 4$ allele, while those who did regular physical exercise or drank moderate amounts of alcohol daily, particularly red wine, had significantly better 
cognitive function. Wine consumption halved the risk of cognitive decline (Figure 3).

$\mathrm{MCI}$ is usually defined as isolated memory impairment in an otherwise healthy individual, and is associated with an annual risk for AD of up to $25 \% .^{71}$ In the US NHLBI twin study of 514 pairs of male twins born between 1917 and 1927, subjects with MCI were older, consumed less alcohol and had an increased prevalence of the APOE $\varepsilon 4$ genotype than normal subjects. ${ }^{72}$ A significantly reduced risk for MCI (RR 0.93) was associated with moderate alcohol consumption. In the CAIDE study in Finland, 1484 subjects were followed up for an average of 23 years; participants who drank no alcohol at midlife and those who drank frequently were twice as likely to have MCI in old age than those who drank infrequently. ${ }^{43}$ Risks of both MCI and dementia increased with increasing alcohol consumption only in those individuals carrying the APOE $\varepsilon 4$ allele.

A more recent Italian study ${ }^{15}$ followed a cohort of 1,445 noncognitively impaired individuals as well as a separate cohort of 121 patients with MCI, aged 65-84 years, for 3.5 years, which is a period when many of the MCI patients would be expected to progress to dementia. ${ }^{71}$ In the MCI group, both moderate drinkers ( $<15 \mathrm{~g}$ alcohol daily) of alcohol and, separately, of wine only, showed significantly lower rates of progression to dementia than abstainers (HR 0.15 for both groups). Higher levels of drinking did not lead to a similar reduction in risk of progression to dementia. Neither alcohol nor wine at any level of drinking altered the incidence of new cases of MCI in the noncognitively impaired group of subjects.

\section{Biological mechanisms for the effects of alcohol and wine}

Human data are scarce on the possible biological mechanisms involved in the protective effects of alcohol and wine against the onset of dementia. Certainly, the findings in the Cardiovascular Health Study that moderate consumption of alcohol, 1-6 drinks per week, reduced carotid artery atherosclerosis in older adults compared with abstainers could partly explain the benefits in reducing the risks of stroke and $\mathrm{VaD}$, and, possibly, AD. ${ }^{73}$ Also, older subjects without dementia living in Rotterdam had significantly less severe white matter lesions and fewer brain infarcts on MRI if they were light to moderate drinkers-one drink weekly to one drink daily, or one drink daily to less than four drinks daily-than did abstainers or heavy drinkers. ${ }^{74}$ Abstainers and heavy drinkers additionally had smaller hippocampal and amygdalar volumes on MRI than did light to moderate drinkers, but only if the former carried the APOE $\varepsilon 4$ allele.

Alcohol, including wine, has well established properties that contribute to its protective effect against CHD, stroke and diabetes, namely antiatherosclerotic and antithrombotic effects and a major influence on glucose metabolism (Table 3). Some of these effects will undoubtedly contribute to the protective effects against dementia, which involves a number of processes including vascular changes, more pronounced perhaps in $\mathrm{VaD}$ than $\mathrm{AD}$. It is interesting to note

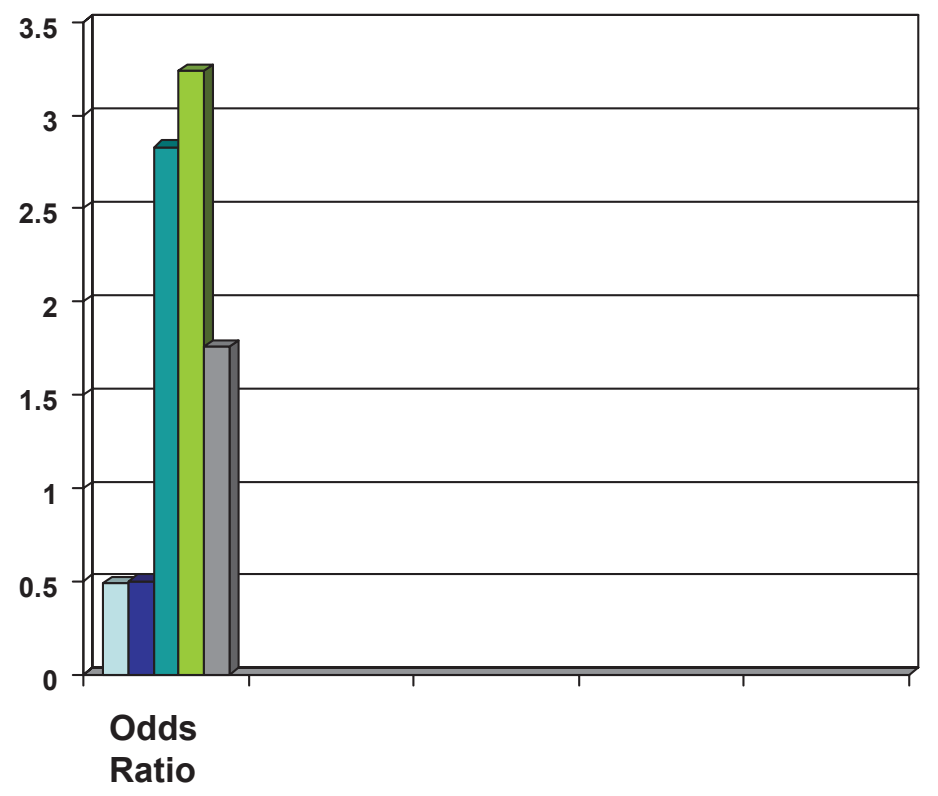

$\square$ Alcohol (red wine)
$\square$ Physical Exercise
$\square$ Metabolic Syndrome
$\square$ Depression
$\square$ APO E4 carrier

Figure 3 Danish case control study: Risk factors for cognitive impairment in the elderly. ${ }^{70}$ 
that impaired insulin secretion increases the risk of $\mathrm{AD}^{75}$ and that proper control of diabetes with insulin and antidiabetic medications results in less $\mathrm{AD}$ neuropathology. ${ }^{76} \mathrm{AD}$ has been termed "type 3 diabetes" because of the debilitating effect of amyloid beta $(A \beta)$ oligomers on neuronal insulin receptors in the brain. ${ }^{77}$

The anti-inflammatory properties of alcohol and wine will also play a role. Wine polyphenols, for example, have been shown to inhibit COX-2 mRNA expression in rat brain. ${ }^{78}$ It has long been known that inflammatory processes are probably involved in the development of $\mathrm{AD}$ pathology based upon extensive laboratory evidence. ${ }^{79,80}$ A review of 17 large epidemiological studies suggested that arthritis and anti-inflammatory drugs are possible protective factors for AD. ${ }^{81}$ Long-term use of NSAIDs in humans is associated with a halving of the risk of $\mathrm{AD}$, as shown by a large meta-analysis of 25 community-based cohort and case control studies. ${ }^{82}$ The benefit may be greatest with ibuprofen. ${ }^{83}$ However, some randomized clinical trials of particular NSAIDs have failed to show benefit, possibly because of a too short duration of treatment or a lack of deterioration on placebo. ${ }^{21,22,84}$ Some NSAIDs, like ibuprofen and flurbiprofen, are inhibitors of $\gamma$-secretase and thereby reduce $A \beta$ processing and deposition. ${ }^{85}$ Flurizan, the R-enantiomer of flurbiprofen, is in clinical phase III trials for the treatment of AD. ${ }^{86}$

Alcohol, and wine, might also have a direct effect upon cognition by stimulating release of acetylcholine in the hippocampus, for which there is experimental evidence. ${ }^{87,88}$ Data are lacking, however, on a possible association between alcohol consumption and use of current $\mathrm{AD}$ treatments which target release of acetylcholine.

Table 3 Effects of alcohol which protect against CHD, stroke and dementia ${ }^{5,79,80,103,105}$

\footnotetext{
- Antiatherosclerotic:

- Increased levels of high-density lipoprotein cholesterol (HDL)

- Preserved HDL-associated paraoxonase

- Reduced LDL peroxidation

- Reduced macrophage atherogenicity and formation of foam cells

- Increased levels of apolipoprotein A

- Reduced levels of C-reactive protein

- Antithrombotic:

- Decreased levels of fibrinogen

- Decreased platelet aggregation, and additive effects with aspirin

- Increased thromboxane-prostacyclin ratio

- Increased release of plasminogen activator

- On glucose metabolism:

- Decreased blood glucose levels

- Enhanced insulin sensitivity and decreased insulin resistance

- Anti-inflammatory

- Reduction of $A \beta$ processing
}

The fact that wine seems to be more effective than alcohol in most of the studies that evaluated the association between consumption and the risk of dementia (Table 2) suggests that there is something different about the ways by which alcohol and wine produce their effects. Unlike beer and spirits, wine contains a variety of polyphenolic molecules which are extracted from the grapes during vinification, mostly in the form of members of the flavonoid (eg, quercetin) and stilbene (eg, resveratrol) chemical families and contained in grape tannins and anthocyanin pigments. ${ }^{89}$ Polyphenol content is higher in red than in white or rosé wines because of the greater degree of extraction during fermentation, and may vary between grape varieties and geographical regions. Top varieties for polyphenol content are Pinot Noir and Merlot, as well as many of the artisanal wines made from ancient varietals found in the Mediterranean area, especially in Sardinia and south-west France. ${ }^{90}$ Wine polyphenols have pronounced antioxidant properties, although they are present in wines at quite low levels, corresponding to about $250 \mathrm{mg} / \mathrm{l}$ in white and $1500 \mathrm{mg} / \mathrm{l}$ in red wines. Polyphenol content declines as wines age, which argues for drinking them young and tannic to gain the health benefits in CHD, stroke, diabetes, and dementia.

Wine has unique properties quite separately from its alcohol content because of the polyphenols, which possess potent antioxidant activity and a host of mechanisms which will promote efficacy in $\mathrm{AD}$ and $\mathrm{VaD}$ (Table 4). The low content of polyphenols in all wines makes it unlikely that they act purely through their antioxidant activity, but they will play a part in increasing levels of endothelial nitric oxide ${ }^{91}$ and in reducing endothelin-1 synthesis ${ }^{92}$ which will surely influence atherosclerotic processes in $\mathrm{VaD}$ and possibly $\mathrm{AD}$. Doré ${ }^{93}$ has pointed out that wine polyphenols have major effects on gene and protein expression in the brain, which go beyond their direct antioxidant actions and may occur at much lower doses than are obtained by drinking moderate amounts of wine. Nevertheless, AD neuropathology, especially plaque formation, does involve oxidative processes, while normal aging has been ascribed to the production of free radicals, ${ }^{94,95}$

Table 4 Unique effects of wine polyphenols which may protect against dementiaia ${ }^{90-93,97,98,101,102}$

- Reduced endothelin-I synthesis

- Increased levels of endothelial nitric oxide

- Improvement of mitochondrial function

- Stimulation of sirtuin activity

- Clearance of amyloid beta $(A \beta)$ neuropathology

- Modulation of the expression of genes and proteins 
processes which would undoubtedly be inhibited by wine polyphenols but not by beer or spirits.

Diminished mitochondrial function and metabolic homeostasis is associated with reduced longevity as a result of decreased activity of a family of NAD+-dependent protein deacetylases called sirtuins. Sirtuins may play a role in protecting neurons against damage and prolonging their survival in AD. ${ }^{96}$ One of the principal wine polyphenols, resveratrol, has been shown to extend life span in yeasts. ${ }^{97}$ Dietary resveratrol improved mitochondrial activity and metabolic homeostasis in mice..$^{98}$ It also improved health and survival of mice on a high-calorie diet, ${ }^{99}$ and retarded aging in mice by mimicking calorie restriction. ${ }^{100}$ The effects of resveratrol were associated with an induction of genes for oxidative phosphorylation and mitochondrial biogenesis. Synthetic analogues of resveratrol are under investigation, and one, SRT501, is in clinical trials for the treatment of obesity.

Just like some NSAIDs, wine polyphenols appear to attenuate $\mathrm{AD}$ neuropathology by acting upon the $\mathrm{A} \beta$ peptide system but via a different mechanism of action. Resveratrol markedly lowered the levels of secreted and intracellular $\mathrm{A} \beta$ peptides produced from different cell lines in vitro. ${ }^{101}$ Unlike the NSAIDs, it did not appear to inhibit $A \beta$ production directly, having no effect upon the $\beta$ - and $\gamma$-secretase enzymes which produce $A \beta$, but rather promoted intracellular degradation of $A \beta$ via a mechanism that involved the proteasome. Indeed, the resveratrol-induced decrease of $A \beta$ could be prevented by several selective proteasome inhibitors. Confirmation of these findings have emerged from an in vivo study in a mouse model of AD. ${ }^{102}$ Using Tg2756 mice, which model AD-type $\mathrm{A} \beta$ neuropathology and cognitive changes, moderate consumption of Cabernet Sauvignon red wine altered both pathology and cognition. Compared to control groups receiving ethanol or water, the wine significantly attenuated AD-type deterioration of spatial memory function and $A \beta$ neuropathology. The effect is attributed to promotion by red wine of nonamyloidogenic processing of amyloid precursor protein, which ultimately prevents the generation of $A \beta$ peptides.

\section{Conclusions}

Although an association does not imply causality, there is substantial evidence from population-based cohort and casecontrol studies that moderate and regular consumption of alcohol is associated with a lesser risk of cognitive decline in old age and of dementia particularly of AD and possibly also of $\mathrm{VaD}$. It may also inhibit the progression of MCI to $\mathrm{AD}$. In general, it appears that the benefit is less in those individuals carrying the APOE $\varepsilon 4$ allele. Wine, particularly red, may offer the most benefit, and women seem to benefit more than men especially in terms of cognitive decline.

However, wine drinkers may have different behavioral characteristics than abstainers or drinkers of other alcoholic beverages, which can confound hard conclusions. The J-shaped curve is common, whereby moderate drinking is at the nadir of the J, with abstention and heavy drinking on the short and long arms respectively. Wine is a part of the Mediterranean diet, which has also been shown to reduce the risk of $\mathrm{AD}$ along with physical exercise. Plausible biological mechanisms explain the benefit of alcohol and wine. As Klatsky ${ }^{14}$ has pointed out for CHD and alcohol, relative specificity of the inverse relation of moderate drinking to dementia is a strong point for causality.

\section{Disclosure}

The author reports no conflict of interest in this work.

\section{References}

1. Norrie PA. The history of wine as a medicine. In: Sandler M, Pinder R, editors. Wine. A Scientific Exploration. London: Taylor and Francis; 2003. p. $21-55$.

2. Sandler M, Pinder R, editors. Wine. A Scientific Exploration. London: Taylor and Francis; 2003.

3. Di Castelnuovo A, Rotondo S, Iacoviello L, et al. Meta-analysis of wine and beer consumption in relation to vascular risk. Circulation. 2002;105:2836-2844.

4. Klatsky AL, Friedman GD, Armstrong MA, et al. Wine, liquor, beer and mortality. Am J Epidemiol. 2003;158:585-595.

5. Klatsky AL. Wine, alcohol and cardiovascular disease. In: Sandler M, Pinder R, editors. Wine. A Scientific Exploration. London: Taylor and Francis; 2003. p. 108-139.

6. Di Castelnuovo A, Costanzo S, Bagnardi V, et al. Alcohol dosing and total mortality in men and women. An updated meta-analysis of 34 prospective studies. Arch Intern Med. 2006;166:2437-2445.

7. Beulens JWJ, Rimm E, Aschiero A, et al. Alcohol consumption and risk for coronary heart disease among men with hypertension. Arch Intern Med. 2007;146:10-19.

8. Djoussé L, Gaziano JM. Alcohol consumption and heart failure in hypertensive US male physicians. Am J Cardiol. 2008;102:593-597.

9. Reynolds K, Lewis LB, Nolen JDJ, et al. Alcohol and the risk of stroke. A meta-analysis. JAMA. 2003;289:579-588.

10. Pinder RM, Sandler M. Alcohol, wine and mental health: focus on dementia and stroke. J Psychopharmacol. 2004;18:449-456.

11. Carlsson S, Hammar N, Grill V, et al. Alcohol consumption and the incidence of type 2 diabetes. A 20-year follow-up of the Finnish twin cohort. Diabetes Care. 2002;26:2785-2790.

12. Koppes LJ, Bouter LM, Dekker JM, et al. Moderate alcohol consumption lowers the risk of type 2 diabetes. A meta-analysis of prospective observational studies. Diabetes Care. 2005;28:719-725.

13. Davies MJ, Baer DJ, Judd JT, et al. Effects of moderate alcohol intake on fasting insulin and glucose concentrations and insulin sensitivity in postmenopausal women. A randomized controlled trial. JAMA. 2002;287:2559-2562.

14. Klatsky AL. Is it the drink or the drinker? Circumstantial evidence only raises a probability. Am J Clin Nutr. 1999;69:2-3.

15. Solfrizzi V, D'Introno A, Colacicco AM, et al. Alcohol consumption, mild cognitive impairment, and progression to dementia. Neurology. 2007;68:1790-1799. 
16. Peters R, Peters J, Warner J, et al. Alcohol, dementia and cognitive decline in the elderly: a systematic review. Age Ageing. 2008;37:505-512.

17. World Health Organization, World Federation of Neurology. Atlas of Country Resources for Neurological Disorders. Geneva: WHO; 2004.

18. Husain MM, Trevino K, Siddique H, et al. Present and prospective clinical therapeutic regimens for Alzheimer's disease. Neuropsychiat Dis Treat. 2008:4:765-777.

19. Pinder RM. Is Alzheimer's a preventable disease? Ann Gen Psychiatry. 2008;7(Suppl 1):S59.

20. Solfrizzi V, Capurso C, D'Introno A, et al. Lifestyle-related factors in predementia and dementia syndromes. Expert Rev Neurother. 2008;8:133-158.

21. ADAPT Research Group. Naproxen and celecoxib do not prevent $\mathrm{AD}$ in early results from a randomized controlled trial. Neurology. 2007;68:1800-1808.

22. ADAPT Research Group. Cognitive function over time in the Alzheimer's Disease Anti-inflammatory Prevention Trial (ADAPT). Arch Neurol. 2008;65:896-905.

23. Garibotto V, Borroni B, Kalbe E, et al. Education and occupation as proxies for reserve in aMCI converters and AD. Neurology. 2008; 71:1342-1349.

24. Sofi F, Cesari F, Abbate R, et al. Adherence to Mediterranean diet and health status: meta-analysis. BMJ. 2008;337:a1344.

25. Scarmeas N, Stern Y, Tang M-X, et al. Mediterranean diet and risk for Alzheimer's disease. Ann Neurol. 2006;59:912-921.

26. Scarmeas N, Luchsinger JA, Mayeux R, et al. Mediterranean diet and Alzheimer disease mortality. Neurology. 2007;69:1084-1093.

27. Barberger-Gateau P, Raffaitin C, Letenneur L, et al. Dietary patterns and risk of dementia. The Three-City Cohort Study. Neurology. 2008;69:1921-1930.

28. Larrieu S, Letenneur L, Helmer C. et al. Nutritional factors and risk of incident dementia in the PAQUID longitudinal cohort. J Nutr Health Aging. 2004;8:150-154.

29. Bobak M, Marmot M. Wine and heart disease: a statistical approach. In: Sandler M, Pinder R, editors. Wine. A Scientific Exploration. London: Taylor and Francis; 2003. p. 92-107.

30. Letenneur L. Moderate alcohol consumption and risk of developing dementia in the elderly: the contribution of prospective studies. Ann Epidemiol. 2007;17:S43-S45.

31. Mukamal KJ, Conigrave KM, Mittleman MA, et al. Role of drinking pattern and type of alcohol consumed in coronary heart disease in men. N Engl J Med. 2003;348:109-118.

32. Mukamal KJ, Jensen KJ, Grønbæk M, et al. Drinking frequency, mediating biomarkers, and risk of myocardial infarction in women and men. Circulation. 2005;112:1406-1413.

33. Mukamal KJ, Ascherio A, Mittleman MA, et al. Alcohol and risk for ischemic stroke in men; The role of drinking patterns and usual beverage. Ann Intern Med. 2005;142:11-19.

34. Mukamal KJ, Maclure M, Muller JE, et al. Binge drinking and mortality after acute myocardial infarction. Circulation. 2005;112: 3839-3845.

35. Jarvenpaa T, Rinne JO, Koskenvuo M, et al. Binge drinking in midlife and dementia risk. Epidemiology. 2005;16:766-771.

36. St Leger AS, Cochrane AL, Moore F. Factors associated with cardiac mortality in developed countries with particular reference to the consumption of wine. Lancet. 1979;1:1017-1020.

37. Hébert R, Scherr PA, Beckett LA, et al. Relation of smoking and alcohol consumption to incident Alzheimer's disease. Am J Epidemiol. 1992;135:347-355.

38. Hébert R, Lindsay J, Verreault R, et al. Vascular dementia: Incidence and risk factors in the Canadian Study of Health and Aging. Stroke. 2000;31:1487-1493.

39. Broe GA, Creasy H, Jorm AF, et al. Health habits and risk of cognitive impairnment and dementia in old age: A prospective study on the effects of exercise, smoking and alcohol consumption. Austral NZ J Publ Health. 2008;22:621-623.
40. Yoshitake T, Kiyohara Y, Kato I, et al. Incidence and risk factors of vascular dementia and Alzheimer's disease in a defined elderly Japanese population: the Hisayama Study. Neurology. 1995;45:1161-1168.

41. Simons LA, Simons J, McCallum J, et al. Lifestyle factors and risk of dementia: the Dubbo Study of the elderly. Med J Aust. 2006;184:68-70.

42. Kivipelto M, Helkala E-L, Laakso MP, et al. Midlife vascular risk factors and Alzheimer's disease in later life: longitudinal, populationbased study. BMJ. 2001;322:1447-1451.

43. Anttila T, Helkala E-L, Viitanen M, et al. Alcohol drinking in middle age and subsequent risk of mild cognitive impairment and dementia in old age: a prospective population-based study. BMJ. 2004;329:539-544.

44. Orgogozo JM, Dartigues JF, Lafont S, et al. Wine consumption and dementia in the elderly: a prospective community study in the Bordeaux area. Rev Neurol. 1997;153:185-192.

45. Leibovici, D, Ritchie K, Ledesert L, et al. The effects of wine and tobacco consumption on cognitive performance in the eldely: a longitudal study of relative risk. Int J Epidemiol. 1999;28:77-81.

46. Ruitenberg A, van Swieten JC, Witteman JC, et al. Alcohol consumption and risk of dementia: the Rotterdam study. Lancet. 2002;359: 281-286.

47. Luchsinger J, Tang MX, Siddiqui M, et al. Alcohol intake and risk of dementia. J Am Geriatr Soc. 2004;52:540-546.

48. Lindsay J, Laurin D, Verreault R, et al. Risk factors for Alzheimer's disease: A prospective analysis of the Canadian Study of Health and Aging. Am J Epidemiol. 2002;156:445-453.

49. Huang W, Qiu C, Winblad B, et al. Alcohol consumption and incidence of dementia in a community sample aged 75 years and older. $J$ Clin Epidemiol. 2002;55:959-964.

50. Deng J, Zhou DH, Li J, et al. A 2-year follow-up study of alcohol consumption and risk of dementia. Clin Neurol Neurosurg. 2006;108:378-383.

51. Zhou DHD, Wang JYJ, Li J, et al. Study on frequency and predictors of dementia after ischaemic stroke. J Neurol. 2004;251:421-427.

52. Mukamal KJ, Kuller L, Fitzpatrick A, et al. Prospective study of alcohol consumption and risk of dementia in older adults, JAMA. 2003b; 289:1405-1413.

53. Truelsen T, Thudium D, Grønbæk M. Amount and type of alcohol and risk of dementia. The Copenhagen Heart Study. Neurology. 2002;59:1313-1319.

54. Mehlig K, Skoog I, Guo X, et al. Alcoholic beverages and incidence of dementia: 34-year follow-up of the Prospective Population Study of Women in Göteborg. Am J Epidemiol. 2008;167:684-691.

55. Zuccala G, Onder G, Pedone C, et al. Dose-related impact of alcohol consumption on cognitive function in advanced age: results of a multicentre survey. Alcohol Clin Exp Res. 2001;25:1743-1748.

56. Hébert LE, Scherr PA, Beckett LA, et al. Relation of smoking and low-to-moderate alcohol consumption to change in cognitive function: A longitudinal study in a defined community of older persons. Am J Epidemiol. 1993;137:881-891.

57. Dufouil C, Ducimetiere P, Alperovitch A. Sex differences in the association between alcohol consumption and cognitive performance. EVA Study Group. Epidemiology of Vascular Aging. Am J Epidemiol. 1997;146:405-412.

58. Elias PK, Elias MF, D'Agostino RB, et al. Alcohol consumption and cognitive performance in the Framingham Heart Study. Am J Epidemiol. 1999;150:580-589.

59. Kalmijn S, van Boxtel MPJ, Verschuren MWM, et al. Cigarette smoking and alcohol consumption in relation to cognitive performance in middle age. Am J Epidemiol. 2002;156:936-944.

60. Launer LJ, Feskens EJ, Kalmijn S, et al. Smoking, drinking and thinking. The Zutphen Elderly Study. Am J Epidemiol. 1996;143:219-227.

61. Leroi I, Sheppard J-M, Lyketsos G. Cognitive function after 11.5 years of alcohol use: Relation to alcohol use. Am J Epidemiol. 2002; 156:747-752.

62. Britton A, Singh-Manoux A, Marmot M. Alcohol consumption and cognitive function in the Whitehall Study. Am J Epidemiol. 2004; 160:240-247. 
63. Stampfer MJ, Kang JH, Chen J, et al. Effects of moderate alcohol consumption on cognitive function in women. $N$ Engl J Med. 2005;352:245-253.

64. Espeland MA, Gu L, Masaki KH, et al. Association between reported alcohol intake and cognition: Results from the Women's Health Initiative Memory Study. Am J Epidemiol. 2005;161:228-238.

65. Wright CB, Elkind MSV, Luo X, et al. Reported alcohol consumption and cogntive decline: The Northern Manhattan Study. Neuroepidemiology. 2006;27:201-207.

66. Byles J, Young A, Furuya H, et al. A drink to healthy aging: The association between older women's use of alcohol and their healthrelated quality of life. J Am Geriatr Soc. 2006;54:1341-1347.

67. Ngandu T, Helkala E-L, Soinen H, et al. Alcohol drinking and cognitive functions: Findings from the Cardiovascular Risk Factors Aging and Dementia (CAIDE) Study. Dement Geriatr Cogn Disord. 2007; 23:140-149.

68. Ganguli M, Van der Bilt J, Saxton JA, et al. Alcohol consumption and cognitive function in late life. A longitudinal community study. Neurology. 2005;65:1210-1217.

69. Lindeman RD, Wayne SJ, Baumgartner RN, et al. Cognitive function in drinkers compared to abstainers in the New Mexico Elder Health Study. J Gerontol Series A. 2005;60:1065-1070.

70. Rasmussen HB, Bagger YZ, Tanko LB, et al. Cognitive impairment in elderly women: the relative importance of selected genes, lifestyle factors, and co-morbidities. Neuropsychiat Dis Treat. 2006;2:227-233.

71. Dawe B, Procter A, Philpot M. Concepts of mild cognitive impairment in the elderly and their relationship to dementia: A review. Int J Geriatr Psychiatry. 1992;7:473-479.

72. DeCarli C, Miller BL, Swan GE, et al. Cerebrovascular and brain morphological correlates of mild cognitive impairment in the National Heart, Lung, and Blood Institute Twin Study. Arch Neurol. 2001;58:643-647.

73. Mukamal KJ, Kronmal RA, Mittleman MA, et al. Alcohol consumption and carotid atherosclerosis in older adults. The Cardiovascular Health Study. Arterioscler Thromb Vasc Biol. 2003c;23:2252-2259.

74. Den Heijer T, Vermeer SE, Van Dijk EJ, et al. Alcohol intake in relation to brain magnetic resonance imaging findings in older persons without dementia. Am J Clin Nutr. 2004;80:992-997.

75. Rönnemaa E, Zethelius B, Sundelöf J, et al. Impaired insulin secretion increases the risk of Alzheimer disease. Neurology. 2008;71:1065-1071.

76. Beeri MS, Schmeidler J, Silverman JM, et al. Insulin in combination with other diabetes medication is associated with less Alzheimer neuropathology. Neurology. 2008;71:750-757.

77. Zhao W-Q, De Felice FG, Fernandez S, et al. Amyloid beta oligomers induce impairment of neuronal insulin receptors. FASEB J. 2008;22:246-260.

78. Simonyi A, Woods D, Sun AY, et al. Grape polyphenols inhibit chronic ethanol-induced COX-2 mRNA expression in rat brain. Alcohol Clin Exp Res. 2002;26:352-357.

79. Aisen WL. Inflammation and Alzheimer's disease: mechanisms and therapeutic strategies. Gerontology. 1997;43:143-149.

80. Akiyama H, Barger S, Barnum S. Inflammation and Alzheimer's disease. Neurobiol Aging. 2000;21:383-421.

81. McGeer PL, Schulzer M, McGeer EG. Arthritis and anti-inflammatory agents as possible protective factors for Alzheimer's disease. Neurology. 1996;47:425-432.

82. De Craen AJM, Gussekloo J, Vrijsen B, et al. Meta-analysis of nonsteroidal antiinflammatory drug use and risk of dementia. Am J Epidemiol. 2005;161:114-120.
83. Vlad SC, Miller DR, Kowall NW, et al. Protective effects of NSAIDs on the development of Alzheimer disease. Neurology. 2008;70: $1672-1677$.

84. Aisen PS, Schafer KA, Grundman M, et al. Effects of rofecoxib or naproxen versus placebo on Alzheimer's disease progression: A randomized controlled trial. JAMA. 2003;289:2819-2826.

85. Weggen S, Eriksen H, Das P, et al. A subset of NSAIDs lower amyloidogenic A $\beta 42$ independently of cyclooxygenase activity. Nature. 2001;414:212-216.

86. Hogan DB. Progress update: Pharmacological treatment of Alzheimer's disease. Neuropsychiat Dis Treat. 2007;3:569-578.

87. Fadda F, Rossetti ZL. Chronic ethanol consumption: from neuroadaptation to neurodegeneration. Progr Neurobiol. 1998;56:385-431.

88. Perry E, Walker M, Grace J, et al. Acetylcholine in mind: A neurotransmitter correlate of consciousness? Trends Neurosci. 1999;22: 273-280

89. Creasy GL, Creasy LL. Grape-derived flavonoids and stilbenes. In: Sandler M, Pinder R, editors. Wine. A Scientific Exploration. London: Taylor and Francis; 2003. p. 199-227.

90. Corder R. The Wine Diet. London: Little, Brown; 2006.

91. Wallerath J, Poleo D, Li H, et al. Red wine increases the expression of human endothelial nitric oxide synthase. J Am Coll Cardiol. 2003;41:471-478

92. Corder R, Douthwaite JA, Lees DM, et al. Endothelin-1 synthesis reduced by red wine. Nature. 2001;414:663-664.

93. Doré S. Unique properties of polyphenol stilbenes in the brain: More than direct antioxidant actions, gene/protein regulatory activity. $\mathrm{Neu}$ rosignals. 2005; 14:61-70.

94. Mattson MF, Rydel RE. Amyloid ox-tox transducers. Nature. 1996;382:674-675.

95. Thomas T, Thomas G, McLendon C, et al. b-Amyloid-mediated vasoactivity and vascular endothelial damage. Nature. 1996;380:168-171.

96. Anekonda TS, Reddy PH. Neuronal protection by sirtuins in Alzheimer's disease. Int J Neurochem. 2006;96:305-313.

97. Howitz KT, Bitterman KJ, Cohen HY, et al. Small molecule activators of sirtuins extend Saccharomyces cerevisiae lifespan. Nature. 2003;425:191-196.

98. Lagouge M, Argmann C, Gerhart-Hines Z, et al. Resveratrol improves mitochondrial function and protects against metabolic disease by activating SIRT1 and PGC-1 $\alpha$. Cell. 2006;127:1109-1122.

99. Bauer JA, Pearson KJ, Price NL, et al. Resveratrol improves health and survival of mice on a high-calorie diet. Nature. 2006;444:337-342.

100. Barger JL, Kaye T, Vann JM, et al. A low dose of dietary resveratrol partially mimics calorie restriction and retards aging parameters in mice. PLoS ONE. 2008;3(6):e2264. doi:10.1371/journal. pone. 0002264

101. Marambaud P, Zhao H, Davies P. Resveratrol promotes clearance of Alzheimer's disease amyloid- $\beta$ peptides. J Biol Chem. 2005;280: 37377-37382.

102. Wang J, Ho L, Zhao Z, et al. Moderate consumption of Cabernet Sauvignon attenuates $A \beta$ neuropathology in a mouse model of Alzheimer's disease. FASEB J. 2006;20:2313-2320.

103. Rimm EB, Williams P, Fosher K, et al. Moderate alcohol intake and lower risk of coronary heart disease: meta-analysis of effects on lipids and haemostatic factors. BMJ. 1999;319:1523-1528.

104. Aviram M, Fuhrman B. Wine flavonoids, LDL cholesterol oxidation and atherosclerosis. In: Sandler M, Pinder R, editors. Wine. A Scientific Exploration. London: Taylor and Francis; 2003. p. 140-159.

105. Vogel RA. Vintners and vasodilators. Are French red wines more cardioprotective? J Am Coll Cardiol. 2003;41:479-481. 